\title{
Response Surface Optimization for Extraction of Phenolics from Coconut Testa (Pairings)
}

\author{
K.D.P.P. Gunathilake*, K.V.S.P. Dharmawansa, K.A.U.D. Weerasinghe and A.J.N. Gimasha
}

\begin{abstract}
Response surface methodology in conjunction with central composite design (CCD) was performed in the present study to optimize the extraction parameters for assessing maximum yield of total phenolic content and antioxidant capacity from coconut pairings. Solvent concentration (30$100 \%)$, extraction temperature $\left(30-60^{\circ} \mathrm{C}\right)$ and extraction time $(30-90 \mathrm{~min})$ were used as the independent variables. The optimum conditions for extraction of total phenolics and antioxidant capacity from coconut pairings were found to be at ethanol concentration, $47.75 \%(\mathrm{v} / \mathrm{v})$; extraction temperature, $49.84^{\circ} \mathrm{C}$; and extraction time, 68.66 minutes. Under these optimal conditions, the model predicted a maximum response of $18.97 \mathrm{mg} \mathrm{GAE} / \mathrm{g}$ DW total phenolics and $38.09 \mathrm{mg} \mathrm{AAE} / \mathrm{g} \mathrm{DW}$ total antioxidant capacity of coconut pairing extracts and they were in close agreement with predicted values, thus indicating the suitability of the models developed and the success of RSM in optimizing the extraction conditions.
\end{abstract}

Key words: Coconut pairings, phenolics, antioxidant capacity, response surface methodology.

\section{Introduction}

Coconut (Cocos nucifera L.), belongs to the family of the Arecaceae (Palmae) is an important fruit tree and oil plant in tropical and subtropical regions. Apart from the production of major kernel's products, there are other constituents that can be used as raw materials for many industrial products. The agro-industrial processing and production have always resulted in large volumes of waste and leading to waste disposal problems especially in countries where their economy rely heavily on agricultural activities. From the economic and environmental point of views, with the large availability and the composition that always rich in bioactive compounds, reutilization of these wastes for the production of beneficial products would be effective in terms of cost and environmental pollution (Jamaluddin et al., 2016). Coconut testa is a by-product from desiccated coconut industry and it is used as animal feed mainly. Its utilization is very limited despite being a good source of secondary metabolites such as polyphenolic constituents. tocopherol and tocotrienols, which may provide health benefits to human (Oliveira et al., 2011).

Department of Food Science \& Technology, Faculty of Livestock, Fisheries \& Nutrition, Wayamba University of Sri Lanka, Makandura, Gonawila, Sri Lanka.

*kdppgunathilake@yahoo.com, +94776594198, Fax: +94312299870 
According to the latest statistics, several thousand tons coconut testa are produced in Sri Lanka annually and they are usually used as animal feed and sometimes use to extract oil for cosmetics. According to Appaiah et al. (2014), coconut testa coming from desiccated coconut industry is rich in fat and it is about $34.7 \%$ in wet weigh basis. Furthermore, its oil extracts have shown high antioxidant activity and well inhibition effect on oxidation of human lowdensity lipoprotein (Zhao et al., 2012; Zhang et al., 2016). Various studies indicate that phytochemicals such as polyphenols from numerous plant sources exert several healthpromoting functions, including reducing the risks of many chronic diseases such as certain types of cancer, cardiovascular and neurodegenerative diseases (Vita, 2005). Most of these preventive effects of polyphenols are associated with their antioxidant activity towards protecting cells and tissues from oxidative damage by various free radicals and reactive oxygen species (ROS) (Sies \& Stahl, 1995). Therefore, recent trends in food and nutritional research are to identify antioxidants rich dietary sources, separation and purification of bioactives for the formulation of functional foods and nutraceutical preparations. Extraction is the initial and most vital step in the recovery and purification of bioactive compounds from plant sources and many factors such as solvent concentration; extraction temperature, solvent-to-solid ratio etc influence the extraction efficiency and bioactive concentration (Prasad et al., 2011). Therefore, it is necessary to optimize the extraction conditions to obtain the highest bioactives recovery. Response surface methodology (RSM) is a widely used tool to evaluate the effects of multiple factors and their interactions in one or more response variables. Therefore, the objective of the present study was to investigate the optimum extraction conditions for coconut testa to obtain the highest polyphenols content.

\section{Material \& methods}

\subsection{Plant materials and chemicals}

Coconut pairings were collected from cleaned coconut without endosperm and cleaned pairings were oven dried at $48{ }^{\circ} \mathrm{C}$ for $48 \mathrm{~h}$, and ground into powder using a blender and were stored at $-18^{\circ} \mathrm{C}$ until use. All other chemicals used were of analytical grade.

\subsection{Preparation of extracts}

One gram of oven-dried and ground coconut pairing sample was extracted with 20 $\mathrm{mL}$ aqueous ethanol (1:20 solid/liquid ratio) in different concentrations using a rotary shaker (Unimax 1010, Heidolph, Kelheim, Germany) at $400 \mathrm{rpm}$, followed by incubation at different temperatures and times dictated by the experimental design (Table 1). The response surface optimization procedure was designed based on a three-factor inscribed central composite design consisting of solvent concentration $\quad(30-100 \%), \quad$ extraction temperatures $\left(30-60{ }^{\circ} \mathrm{C}\right)$ and extraction duration (30-90 $\mathrm{min})$. The ethanol extracts of the pairings were then filtered through a filter paper and the filtrates were stored at $-18{ }^{\circ} \mathrm{C}$ for analysis.

\subsection{Determination of total polyphenol content}

The total polyphenol content was determined using Folin-Ciocalteu assay (Singleton et al., 1999) with some modification, as described by Gunathilake et al. (2014). Approximately $0.5 \mathrm{~mL}$ of pairings extract and $0.1 \mathrm{~mL}$ of Folin-Ciocalteu reagent $(0.5 \mathrm{~N})$ were mixed and incubated at room temperature for 15 minutes at dark and then sodium carbonate $(7.5 \%, 2.5 \mathrm{~mL})$ was added and incubated for 2 hours at dark. Absorbance was measured at 760 $\mathrm{nm}$ using UV/VIS spectrometer (Optima, SP3000 , and Tokyo, Japan) and gallic acid was used as standard and the amount was expressed as mg of gallic acid equivalents (GAE) per gram dry weight.

\subsection{Determination of total antioxidant capacity}

The total antioxidant capacity of pairings extracts was analyzed according to the method described by Prieto, et al. (1999). Briefly, 0.3 $\mathrm{mL}$ pairings extract and $3 \mathrm{~mL}$ reagent solution (0.6 M sulphuric acid, $28 \mathrm{mM}$ sodium phosphate and $4 \mathrm{mM}$ ammonium molybdate) were incubated at $95^{\circ} \mathrm{C}$ for $90 \mathrm{~min}$, and then the solution was cooled to room temperature 
$\left(30 \pm 2^{\circ} \mathrm{C}\right)$, the absorbance of each solution was measured at $695 \mathrm{~nm}$ spectrophotometrically against a blank and ascorbic acid used as the standard.

\subsection{Experimental design}

Optimization of extraction parameters for the extraction of polyphenols with higher antioxidant capacity from coconut pairings was done using response surface methodology. Effect of three independent variables, ethanol concentration, and extraction temperature and extraction duration on the response variables of total polyphenols and total antioxidant capacity were studied. For this study, a three-factor inscribed central composite design (CCD) was used to optimize the extraction process. The independent variables and the range studied are shown in Table 1 and the selection and range of these three factors were based on previous studies. According to the CCD, twenty randomized experiments including six replicates as the center points were assigned and the total polyphenols and antioxidant capacity of the extracts obtained from each variable combination were analyzed and recorded as in Table 2. Minitab15 software was used for the data analysis and the assumptions of normality and constant variance were checked and confirmed. Regression coefficients, the statistical significance of the model terms (using ANOVA) and to fit the mathematical models of the experimental data that aimed to optimize the overall region for both response variables were done using response surface analysis. A secondorder polynomial model was used to predict the response variables from the response surface analysis as appeared below:

$$
\begin{aligned}
Y= & \beta_{0}+\beta_{1} X_{1}+\beta_{2} X_{2}+\beta_{3} X_{3}+\beta_{1}^{2} X_{1}^{2}+\beta_{2}^{2} X_{2}^{2}+ \\
& \beta_{3}^{2} X_{3}^{2}+\beta_{1} \beta_{2} X_{1} X_{2}+\beta_{1} \beta_{3} X_{1} X_{3}+\beta_{2} \beta_{3} X_{2} X_{3}
\end{aligned}
$$

$\mathrm{Y}=$ predicted dependent variable; $\beta_{0}=$ constant; $\beta_{1}, \beta_{2}$ and $\beta_{3}=$ regression coefficients for the linear effect terms; $\beta_{1}^{2}, \beta_{2}^{2}$ and $\beta_{3}^{2}=$ quadratic effect terms; and $\beta_{1} \beta_{2}, \beta_{1} \beta_{3}$ and $\beta_{2} \beta_{3}=$ interaction effect terms. $X 1, X 2$, and $\mathrm{X} 3$ = independent variables.
The adequacy of the model was predicted through the regression analysis $\left(R^{2}\right)$ and the ANOVA analysis. Response surface plots obtained from the analysis demonstrate the relationship between the studied extration parameters and the response variables (polyhenols and antioxidant capacity). Multiple graphical and numerical optimizations of the experimental data were done to identify the optimum extraction conditions to achieve the maximum recovery of total polyphenols and antioxidant capacity. The predicted extraction conditions that would give higher levels of polyphenols and antioxidant capacity were verified experimentally based on the best extractions conditions obtained with RSM.

\subsection{Results and discussion}

CCD experimental design was performed to optimize the phenolics extraction from coconut testa and three variables were studied at three levels and the experimental design is represented in Table 1. Twenty experiments were performed and the corresponding responses, total phenolics and the total antioxidant capacity values were tabulated in Table 2. There are various factors which can influence on the extraction efficiency bioactive constituents and these include solvent type, solvent concentration, extraction time, extraction temperature and solid to solvent ratio etc. (Alothman et al., 2009). RSM is considered as a powerful tool in optimizing experimental conditions to maximize various responses (Hajj et al., 2012) and this process is commonly used in the optimization of bioactive extraction from various sources such as green leafy vegetables (Gunathilake et al, 2018). For the studies on optimization of extraction of bioactive molecules, extraction is one of the most vital steps in the recovery and purification of bioactives from potential dietary sources (Gunathilake et al., 2017a). The uncoded coefficient values for the experimental designs for total polyphenols and antioxidant capacity of coconut testa are given in Table 3 . The analysed values of total polyphenols and antioxidant capacity at software generated extraction conditions were used for the prediction of an optimum set of extraction parameters and the 
Table 1: Levels of extraction variables for experimental designs

\begin{tabular}{|l|c|c|c|c|c|}
\hline \multirow{2}{*}{ Independent variables } & \multicolumn{5}{|c|}{ Level total phenolics and total antioxidant } \\
capacity
\end{tabular}

Table 2: Central composite design arrangement for extraction of phenolics and total antioxidant capacity of the coconut pairings

\begin{tabular}{|c|c|c|c|c|c|}
\hline Run Order & $\begin{array}{c}\text { Ethanol } \\
\%\end{array}$ & $\begin{array}{c}\text { Extraction } \\
\text { temperature }{ }^{\circ} \mathrm{C}\end{array}$ & $\begin{array}{c}\text { Extraction } \\
\text { duration } \\
\text { (min) }\end{array}$ & $\begin{array}{c}\text { Total } \\
\text { phenolics } \\
\text { (mg GAE/g) }\end{array}$ & $\begin{array}{c}\text { Total antioxidant } \\
\text { capacity (mg } \\
\text { AAE/g) }\end{array}$ \\
\hline 1 & 100.0 & 30.0 & 90.0 & 12.87 & 25.73 \\
\hline 2 & 123.9 & 45.0 & 60.0 & 13.87 & 35.52 \\
\hline 3 & 30.0 & 30.0 & 90.0 & 17.67 & 23.81 \\
\hline 4 & 65.0 & 45.0 & 60.0 & 18.89 & 25.04 \\
\hline 5 & 30.0 & 60.0 & 30.0 & 18.29 & 27.36 \\
\hline 6 & 65.0 & 45.0 & 60.0 & 18.64 & 37.65 \\
\hline 7 & 100.0 & 60.0 & 90.0 & 15.83 & 34.13 \\
\hline 8 & 100.0 & 60.0 & 30.0 & 15.09 & 23.84 \\
\hline 9 & 65.0 & 19.8 & 60.0 & 14.44 & 29.65 \\
\hline 10 & 65.0 & 45.0 & 60.0 & 17.39 & 63.33 \\
\hline 11 & 100.0 & 30.0 & 30.0 & 12.14 & 27.65 \\
\hline 12 & 65.0 & 70.2 & 60.0 & 17.67 & 41.49 \\
\hline 13 & 65.0 & 45.0 & 60.0 & 18.85 & 33.47 \\
\hline 14 & 65.0 & 45.0 & 110.5 & 19.36 & 36.80 \\
\hline 15 & 65.0 & 45.0 & 9.5 & 17.80 & 43.52 \\
\hline 16 & 30.0 & 30.0 & 30.0 & 14.90 & 25.92 \\
\hline 17 & 30.0 & 60.0 & 90.0 & 17.11 & 50.93 \\
\hline 18 & 65.0 & 45.0 & 60.0 & 18.18 & 31.89 \\
\hline 19 & 65.0 & 45.0 & 60.0 & 18.48 & 27.65 \\
\hline 20 & 6.1 & 45.0 & 60.0 & 19.33 & 20.77 \\
\hline
\end{tabular}


multiple regression analysis, performed using RSM to fit the second-order polynomial equations are given in Table 3. The "fitness" of the model was studied through the lack-of-fit test ( $p>0.05$ ), which indicated the adequacy of models to accurately predict the variation as described in Kong et al. (2010). The quality of fit to the second-order polynomial models for extracts of coconut testa was established based on the regression $p$-value $(p<0.1)$ and lack of fit $(p>0.05)$ indicating that the models could be used to predict the responses.

\subsection{Model fitting of parameters}

The levels of independent variables used for the extraction of total polyphenols and antioxidant capacity were selected for the RSM study based on the previous published works. Total polyphenols content of the extracts of coconut testa varied from 12.14 to $19.36 \mathrm{mg}$ GAE/g dry sample. Total antioxidant capacity of the extracts of coconut testa varied from 20.77 to $63.33 \mathrm{mg} \mathrm{AAE} / \mathrm{g}$. There was no significance in the lack of fit $(p=0.05)$ in the models for both polyphenols and antioxidant capacity indicating that the model could be used to predict the responses. Visualization of the relationship between the response and experimental levels of the independent variables for the total polyphenols and antioxidant capacity of different extraction, were done by constructing the threedimensional (3D) surface plots according to the quadratic polynomial model equations of Table 3. Response surface plots shown in Figure 1-2 illustrate the effects of solvent concentration, extraction time and the temperature on the responses. Figure 1 describes the effect of the ethanol concentration, extraction temperature and the duration of the extraction on the recovery of polyphenols from coconut testa. Solvents used for the extraction play an important role in the extraction of polyphenols and other bioactives from complex biological materials. Among the solvent used for bioactive extraction, ethanol is relatively cheap, reusable and nontoxic organic solvent, could lend an environmentally friendly aspect to the low-cost preparation of potentially bioactive extracts for food and nutraceutical uses. Therefore, many researchers have used aqueous ethanol for the extraction of various bioactive antioxidants from plants sources when used for food uses (Gunathilake et al., 2017b; Gunathilake et al., 2018; Hayouni et al., 2007).

The effect of ethanol concentration, extraction temperature and extraction time on and total antioxidant capacity was illustrated in the response surface plots (Figure 1 and 2). Figure 1 reveals the effects of the selected extraction conditions on total phenolic content which gave significant results during optimization of extraction conditions. As reflected in Figure 1a, the predicted response surface showing the effect of extraction temperature and extraction time on total phenolic content at constant ethanol level (65\%) is curved downward indicating phenolic extraction prefers high extraction temperatures. However, it was found that the extraction time was less influence as in Figure 1a. As seen in Figure 1b, a higher amount of phenolic content approximately yielded in the region of ethanol concentration between 55.0 and $65.0 \%$. It is believed that a high ethanol concentration would give a low total phenolic content and according to Zhang et al. (2007) utilization of high solvent concentration in extraction of phenolic compounds should be avoided. The use of water in combination with ethanol contributes to creation of moderately polar medium that ensures the extraction of polyphenols (Chirinos et al. 2007). This is consistent with several other findings also which convey that polyphenols are more extractable in polar solvents as compared to non-polar ones (Prasad et al., 2011; Hayouni et al., 2007). Figure 1c showed that at higher extraction temperature $\left(60^{\circ} \mathrm{C}\right)$, increased the extractable phenolics compared with the use of lower extraction temperature. This could be due to the increase in the solubility of polyphenols, diffusion rate, mass transfer rate, extraction rate and solvent polarities which could improve the phenol extractability (Richter et al., 1996).

Figure 2 shows the response surface plots for the total antioxidant capacity (mg AAE/g DW) of the extracts of coconut pairings as a function of ethanol $\%$, extraction temperature and time; ethanol \% was kept constant at $65 \%$ (2a); temperature of extraction was kept constant 


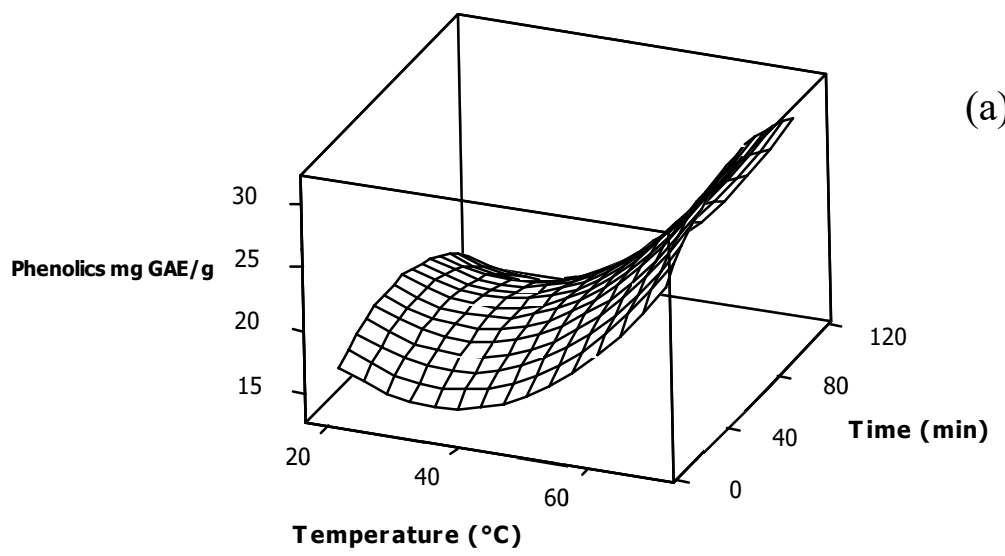

(a)
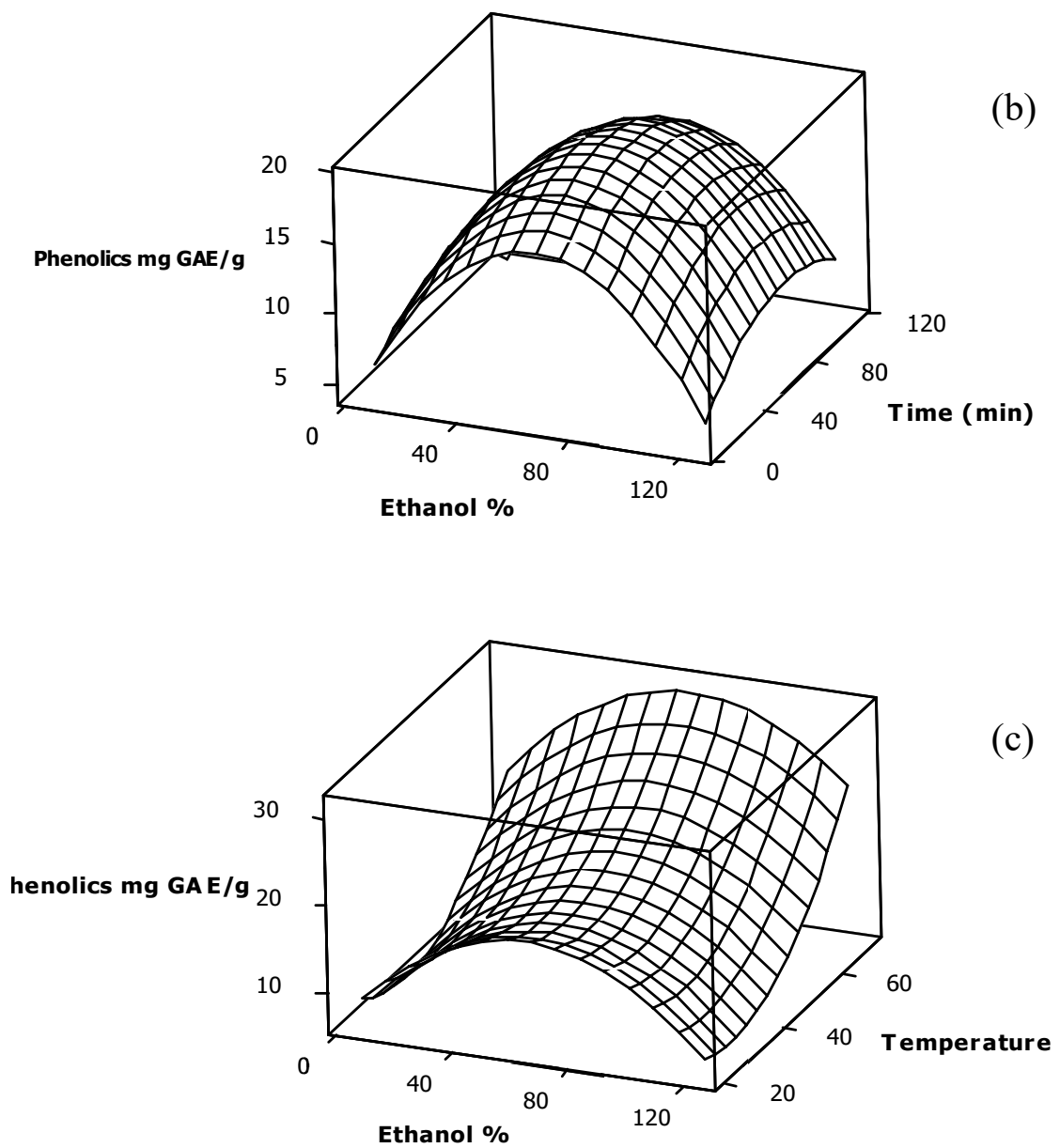

Figure 1. Response surface plots of the phenolics (mg GAE/g DW) extraction from coconut pairings as a function of ethanol \%, extraction temperature and time: ethanol \% was kept constant at $65 \%$ (a); temperature of extraction was kept constant at $45^{\circ} \mathrm{C}$ (b) and the time of extraction was kept constant at $60 \mathrm{~min}(\mathrm{c})$. 


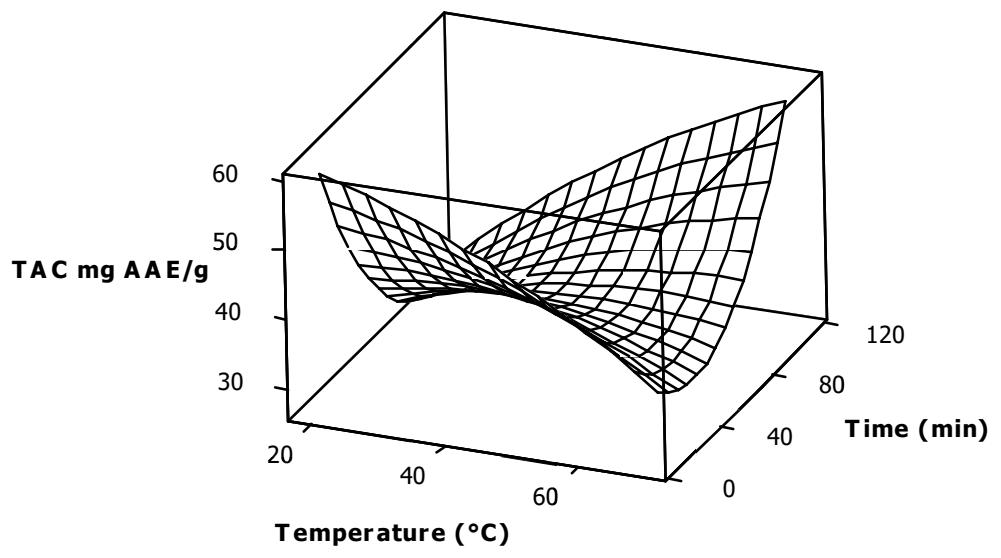

(a)

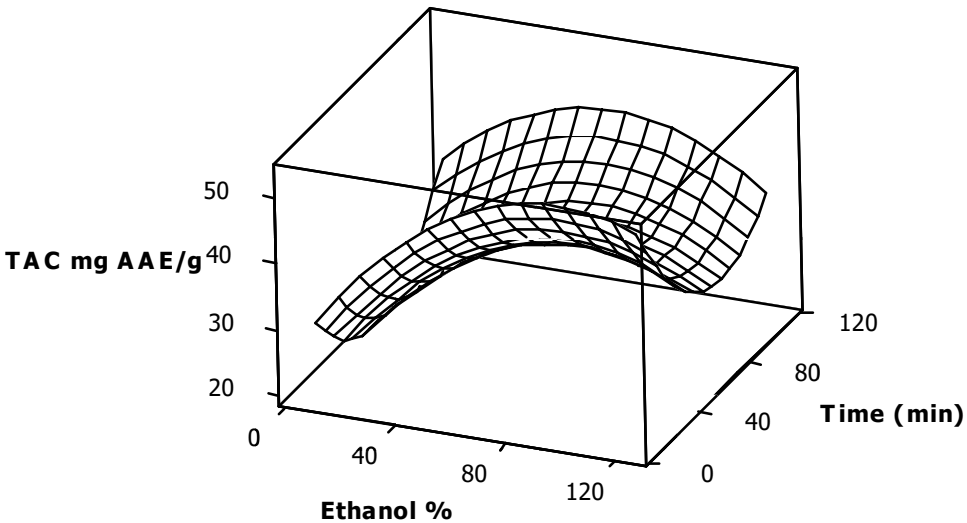

(b)

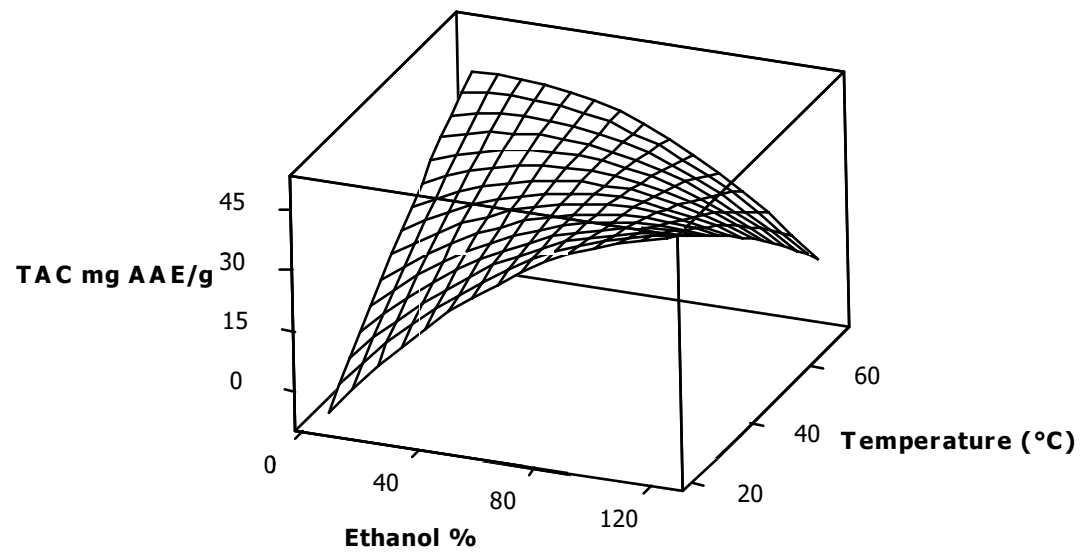

(c)

Figure 2. Response surface plots for the total antioxidant capacity (mg AAE/g DW) of the extracts of coconut pairings as a function of ethanol \%, extraction temperature and time; ethanol \% was kept constant at $65 \%$ (a); temperature of extraction was kept constant at $45^{\circ} \mathrm{C}$ (b) and the time of extraction was kept constant at $60 \mathrm{~min}(\mathrm{c})$. 
Table 3: Estimated regression coefficients of the second-order polynomial equations for RSM analysis of total antioxidant capacity and phenolics extraction

\begin{tabular}{|l|cc|cc|}
\hline & \multicolumn{2}{|c|}{ Total antioxidant capacity } & \multicolumn{2}{c|}{ Total polyphenols } \\
\hline Term & Coefficient & P & Coefficient & P \\
\hline Constant & 2.89188 & 0.954 & 2.20912 & 0.688 \\
ETOH & 0.78379 & 0.171 & 0.00322 & 0.957 \\
TEMP & 0.51814 & 0.723 & 0.55854 & 0.005 \\
TIME & -0.37027 & 0.569 & 0.10811 & 0.148 \\
ETOH*ETOH & -0.00320 & 0.221 & -0.00082 & 0.013 \\
TEMP*TEMP & -0.00577 & 0.675 & -0.00531 & 0.005 \\
TIME*TIME & 0.00036 & 0.916 & -0.00033 & 0.382 \\
ETOH*TEMP & -0.00571 & 0.474 & 0.00113 & 0.208 \\
ETOH*TIME & -0.00156 & 0.693 & 0.00019 & 0.669 \\
TEMP*TIME & 0.01053 & 0.267 & -0.00156 & 0.143 \\
\hline Lack of fit & \multicolumn{3}{|c}{0.160} \\
R $^{2}$ & \multicolumn{3}{|c}{0.862} & $83.57 \%$ \\
\hline
\end{tabular}

Table 4: Predicted values and experimental values of total polyphenols and antioxidant capacity at the optimum extraction conditions

\begin{tabular}{|c|c|c|c|c|}
\hline \multirow{2}{*}{$\begin{array}{l}\text { Optimum extraction conditions to } \\
\text { optimize both responses at same } \\
\text { extraction }\end{array}$} & \multicolumn{2}{|c|}{ Predicted values } & \multicolumn{2}{|c|}{ Experimental values } \\
\hline & $\begin{array}{c}\text { Phenolics } \\
\text { (mg GAE/g) }\end{array}$ & $\begin{array}{c}\text { Total } \\
\text { antioxidant } \\
\text { capacity } \\
\text { (mg AEE/g) }\end{array}$ & $\begin{array}{c}\text { Phenolics } \\
\text { (mg GAE/g) }\end{array}$ & $\begin{array}{c}\text { Total } \\
\text { antioxidant } \\
\text { capacity } \\
\text { (mg AEE/g) }\end{array}$ \\
\hline $\begin{aligned} \mathrm{ETOH} & =47.75 \% \\
\mathrm{TEMP} & =49.84^{\circ} \mathrm{C} \\
\mathrm{TIME} & =68.66 \mathrm{~min}\end{aligned}$ & 18.97 & 38.09 & $16.63 \pm 3.44$ & $34.28 \pm 4.39$ \\
\hline
\end{tabular}

at $45^{\circ} \mathrm{C}(2 \mathrm{~b})$ and the time of extraction was kept constant at $60 \mathrm{~min}(2 \mathrm{c})$. Influence of three extraction conditions towards total antioxidant capacity was reported with the coefficients of the second-order polynomial regression equation as appeared in Table 3. According to the results, it was shown that the antioxidant capacity of the extracts of coconut testa had a lesser influence of ethanol concentration; extraction temperature and time were insignificant $(\mathrm{p}>0.05)$.

\subsection{Optimization of polyphenols and antioxidant capacity and verification of the model}

In order to verify the predictive capability of the model, optimum conditions were established by response surface model and comparisons between the predicted results and the practical values were done by experimental rechecking using those presumed optimal conditions. Table 4 presented the optimum conditions for total phenolics and total antioxidant capacity and their predicted and experimental value. The optimal extraction conditions of total phenolics and total antioxidant capacity from coconut pairing extracts acquired using the model was as follows: ethanol concentration, $47.75 \%(\mathrm{v} / \mathrm{v})$; extraction temperature, $49.84^{\circ} \mathrm{C}$; and extraction time, 68.66 minutes. Under these optimal conditions, the model predicted a maximum response of $18.97 \mathrm{mg} \mathrm{GAE} / \mathrm{g} \mathrm{DW}$ total 
phenolics and $38.09 \mathrm{mg} \mathrm{AAE} / \mathrm{g}$ DW total antioxidant capacity of coconut pairing extracts. A mean value of $16.63 \pm 3.44 \mathrm{mg} \mathrm{GAE} / \mathrm{g}$ DW total phenolics and $34.28 \pm 4.39 \mathrm{mg} \mathrm{AAE} / \mathrm{g}$ total antioxidant capacity of coconut pairing extracts was acquired from real experiments. According to Table 4, it can be observed that the differences between the predicted results and the experimental values under the optimal extraction conditions for both total phenol and antioxidant capacity were insignificant $(p<0.05)$. This demonstrated that the response model was adequate to reflect the expected optimisation.

\section{Conclusions}

The response surface methodology was successfully employed to optimize the extraction conditions on total phenol and antioxidant capacity of coconut pairing extracts. The regression coefficient and $p$-value indicated that ethanol concentration $(p<0.01)(p<0.01)$ was the most significant factor affecting extraction of total phenolic content, followed by extraction temperature. The optimum operating conditions that maximize the extraction of total phenolic and antioxidant capacity were established. In the verification of the predictive capability of the model, it was observed that the differences between the predicted results and the experimental values under the optimal extraction conditions for both total phenol and antioxidant capacity were insignificant indicating that the response models were adequate to reflect the expected optimisation.

\section{References}

Alothman M., Bhat R., Karim A.A. (2009). Antioxidant capacity and phenolic content of selected tropical fruits from Malaysia, extracted with different solvents. Food Chemistry. 115:785-788.

Appaiah, P., Sunil, L., Prasanth Kumar, P.K. and Gopala Krishna, A.G. (2014). Composition of Coconut Testa, Coconut Kernel and Its Oil. Journal of the American Oil Chemists' Society. 91(6): 917-924.

Chirinos, R., Rogez, H., Campos, D., Pedreschi, R. \& Larondelle, Y. (2007). Optimisation of extraction conditions of antioxidant phenolic compounds from mashua (Tropaeolum tuberosum Ruiz \& Pavon) tubers. Journal of Separation and Purification Technology, 5: 217-225.

Gunathilake, K.D.P.P., Ranaweera, K.K.D.S., Rupasinghe, H.P.V., Perera, O.D.A.N., Jayaweera, H.P.S. (2017a). Response surface optimization of extraction of polyphenols and carotenoids from Sesbania grandiflora leaves with ethanolwater system. Asian Journal of Biotechnology and Bioresource Technology. 2(1).

Gunathilake, K.D.P.P., Rupasinghe H.P.V. (2014). Optimization of Water Basedextraction Methods for the Preparation of Bioactiverich Ginger Extract Using Response Surface Methodology. European Journal of Medicinal Plants. 4(8):893.

Gunathilake, K.D.P.P., Ranaweera, K.K.D.S., Rupasinghe, H.P.V. (2017b). Response surface optimization of phenolics and carotenoids extraction from leaves of Olax zeylanica. Annals. Food Science and Technology. 18(3)

Gunathilake KDPP, Ranaweera KKDS, Rupasinghe HPV, R.M. T.R.K. Rathnayaka. (2018). Optimizing the Extraction of Bioactive Compounds from Leaves of Gymnema Lactiferum, an Edible Green Leafy Vegetable. South Asian Research Journal of Natural Products. 1(2): 1-9.

Hayouni, E.A., Abedrabba, M., Bouix, M., Hamdi, M. (2007). The effects of solvents and extraction method on the phenolic contents and biological activities in vitro of Tunisian Quercus coccifera L and Juniperus phoenicea $\mathrm{L}$. fruit extracts. Food Chemistry. 105:1126-1134.

Hajj, Y.E., Louka, N., Nguyen, C., Maroun, R.G. (2012). Low-cost process for phenolic compounds extraction from cabernet sauvignon grapes (Vitis vinifera L. cv. cabernet sauvignon). Optimization by 
response surface methodology. Food Nutr. Science. 3:89-103.

Jamaluddin, A., Razak, D.L.A., Rashid, N.Y.A., Sharifudin, S.A., Kahar, A.Z.M., Saad, A.Z.M. and Long, K. (2016). effects of solid state fermentation by Monascus purpureus on phenolic content and biological activities of coconut testa and rice bran. Jurnal Teknologi,78(11/12), pp.23-28.

Kong, K.W., Ismail, A.R., Tan, S.T., Prasad, K.M.N., Ismail A. (2010). Response surface optimisation for the extraction of phenolics and flavonoids from a pink guava puree industrial by-product. International Journal of Food Science and Technology 45:1739-1745

Oliveira, M.S., Feddern, V., Kupski, L., Cipolatti, E. P., Badiale-Furlong, E., and SouzaSoares, L.A. (2011). Changes in Lipid, Fatty Acids and Phospholipids Composition of Whole Rice Bran After Solid-state Fungal Fermentation. Bioresource Technology. 102: 8335-8338.

Prasad, K.N., Hassan, F.A., Yang, B., Kong, K.W., Ramanan, R.N., Azlan, A., Ismail, A. (2011). Response surface optimisation for the extraction of phenolic compounds and antioxidant capacities of underutilized Mangifera pajang Kosterm peels. Food Chemistry. 128(4):1121-1127.

Prieto, P., Pineda, M., \& Aguilar, M. (1999). Spectrophotometric quantitation of antioxidant capacity through the formation of a phosphomolybdenum complex: Specific application to the determination of vitamin E. Analytical Biochemistry, $269,337-341$.
Richter, B.E., Jones, B.A., Ezzell, J.L., Porter, N.L., Avdalovic, N., Pohl, C. (1996). Accelerated solvent extraction: A technique for sample preparation. Analytical Chemistry. 68:033-1039.

Singleton, V.L., Orthofer, R., \& LamuelaRaventos, R. (1999). Analysis of total phenols and other oxidation substrates and antioxidants by means of FC reagent. Methods in Enzymology, 29, 152-178.

Sies, H. and Stahl, W. (1995). Vitamins E and C, betacarotene, and other carotenoids as antioxidants. American Journal of Clinical Nutrition. 62:1315-1321.

Vita, J.A. (2005). Polyphenols and cardiovascular disease: Effects on endothelial and platelet function. American Journal of Clinical Nutrition. 81:292-297.

Zhao, X.L., Chen, W.J., Zhao, S.L. \& Tang, M.M. (2012). Antioxidative activity of the extractives from coconut testa oil. Chinese Journal of Tropical Crops, 33, 162-165.

Zhang, Z-S., Li, D., Wang, L.J., Ozkan, N., Chen, X.D., Mao, Z-H. \& Yang, H-Z. (2007). Optimisation of ethanol-water extraction of lignans from flaxseed. Journal of Separation and Purification Technology, 57: 17-24.

Zhang, Y., Zheng, Y., Duan, K. and Gui, Q. (2016). Preparation, antioxidant activity and protective effect of coconut testa oil extraction on oxidative damage to human albumin serum, International Journal of Food Science and Technology 2016, 51, 946-953. 